\section{Decerebrate Posturing}

Jacob Kean ${ }^{1}$ and Travis Williams ${ }^{2}$

${ }^{1}$ Department of Physical Medicine and

Rehabilitation, Indiana University School of

Medicine, Indianapolis, IN, USA

${ }^{2}$ Indiana University-Purdue University

Indianapolis, Indianapolis, IN, USA

\section{Synonyms}

Extensor posturing

\section{Definition}

Decerebrate posturing is a pattern of movement commonly produced by extensive forebrain lesions including the subcortex. It is characterized by rigidity, extension of the arms with wrists pronated, extension of the legs, downward pointing of the toes, and sometimes arching of the spine. Decerebrate posturing may be partial or asymmetric. Decerebrate (or extensor) posturing is distinguished from decorticate (or flexor) posturing by the extension of the arms. Decerebrate posturing is generally the result of massive and bilateral forebrain lesions or other damage that includes upper brainstem and sometimes the rostral pons. Common causes include cerebral infarction (stroke), intracranial hemorrhage, primary brain tumor, secondary brain tumor, traumatic head injury, increased intracranial pressure from any cause, brainstem tumor, and metabolic or hepatic encephalopathies.

\section{Cross-References}

Decorticate Posturing

\section{References and Readings}

Posner, J. B., Saper, C. B., Schiff, N. D., \& Plum, F. (2007). Plum and Posner's diagnosis of stupor and coma. New York: Oxford University Press. 